\title{
Attitude of Nursing and Midwifery students towards clinical practice and its associated factors in Northwest Ethiopia: a cross-sectional study
}

\author{
Yosef Aragaw ${ }^{1 *}$, Workinesh Sinishaw ${ }^{2}$, Workinesh Daba $^{2}$ and Maru Mekie $^{3}$
}

\begin{abstract}
Objective: The aim of this study was to assess the attitude of Nursing and Midwifery students towards clinical practice and its associated factors at University of Gondar, Northwest Ethiopia. 2018.

Result: The prevalence of a favorable attitude towards clinical practice was found to be $42.9 \%$ in this study. The odds of having favorable attitude were found to be 2 times higher among students who prepared well for clinical practice $[A O R=2.07,95 \%, C l(1.25,3.44)]$ compared with counterparts. Similarly students who communicate well with clinical staffs $[A O R=1.89,95 \%, \mathrm{Cl}(1.05,3.41)]$, practiced in well-equipped hospital $[\mathrm{AOR}=1.76,95 \%, \mathrm{Cl}(1.01,3.06)]$, and accompanying frequently by a clinical supervisor $[A O R=1.69,95 \%, \mathrm{Cl}(1.02,2.81)]$ were more likely to have favorable attitude compared with counterparts.
\end{abstract}

Keywords: Nursing and Midwifery students, Attitude, Clinical practice

\section{Introduction}

The meaningful correlation between theory and practical education is taking place in a clinical setting [1-5]. One of the bases for quality nursing service is nursing education which encompasses the three domains of learning; knowledge, attitude, and practice [6, 7].

Attitude plays a major role in leading human toward achieving the desired goals, awareness of its consequences, and effective processing of complex information $[5,6,8]$. Students' attitude towards clinical practice could be affected by a clinical environment, student staff interaction, clinical preceptors, and the availability of necessary equipment in a hospital setting $[9,10]$.

Lack of interest in what people do could decrease the quality of work $[5,6,11]$. More than half of all healthcare providers are Midwives and Nurse in the healthcare setting $[5,6]$. Hence, if the attitude of Nursing and

\footnotetext{
*Correspondence: yosefaragaw19@gmail.com

${ }^{1}$ Department of Midwifery, Debre Tabor Health Science College, Debre Tabor, Ethiopia

Full list of author information is available at the end of the article
}

Midwifery professionals is not favorable, the quality of health care could be compromised in a significant manner. In Ethiopia, students join Nursing and Midwifery degree programs directly after completing secondary education which demands intensive clinical training to acquire Nursing and Midwifery competencies [12].

There is a significant incoherence between theory and clinical practice [9] and one of the cause of this discrepancy could be attitude. A positive attitude towards clinical practice enhances effective clinical learning. Whereas, a negative attitude hampers the acquisition of essential clinical skills. Thus, identifying the gap in clinical practice is noteworthy for improving the quality of Nursing and Midwifery educations [13].

\section{Main text \\ Methods}

\section{Study design and population}

An institution based cross-sectional study was employed from March 19 to 26, 2018 on 345 Nursing and Midwifery students at University of Gondar. The University of Gondar (UoG), until 2003 known as Gondar College of 
Medical Sciences. It is the oldest medical school in Ethiopia which was established as the Public Health College in 1954. It is also the pioneer institution to initiate degree Midwifery training program in Ethiopia [12, 14]. The study population was randomly selected regular Nursing and Midwifery students who fulfill the inclusion criteria.

\section{Inclusion and exclusion criteria}

Randomly selected second-year and above regular Nursing and Midwifery students and those who were willing to participate in the study were included. Whereas, all first-year regular Nursing and Midwifery students, and those refused to participate in the study were excluded.

\section{Sample size determination}

A single population proportion formula was used to calculate sample size at $Z \alpha / 2=1.96,95 \%$ confidence interval, $d=0.05$ degree of margin of error, and proportion ( $\mathrm{P}=0.5$ since there was no similar study as far as the authors' knowledge). Thus, the final sample size after adding $10 \%$ non-response rate was 345 by using a correction formula (Fig. 1).

\section{Measurement of variables and definitions}

The attitude towards clinical practice was measured based on the mean of the sum of fifteen attitude questions which was 9.41 points with minimum and maximum scores of 2 and 15 points, respectively. The attitude score was dichotomized as favorable and unfavorable. Attitude scores $\leq 9.41$ was taken as "unfavorable attitude" while $>9.41$ was taken as "favorable attitude."

Well-equipped hospital: Is a hospital which provides all services to be provided at a hospital level using the current available laboratory setting. Adequacy of rooms were also considered in this study.

Accompanied frequently: In this study accompanied frequently by a clinical supervisor is considered if the clinical supervisor is available with students at least 3 days a week.

Communicate well: Students who interact with staffs in every procedure were considered as communicate well with staffs in this study.

\section{Data collection process and quality assurance}

The calculated sample was allocated to the selected Departments based on the number of students per years of study. Then study participants were selected by a simple random sampling technique from each year of study using students' registration. Data were collected by a selfadministered questionnaire prepared in English after orienting the selected participants. The questionnaire was adapted from previously published literature $[1,3,7,15$,
16]. Content validity of each questionnaire was evaluated based on the review of nine experts in the field of Nursing and Midwifery. Experts' ratings were used to calculate the content validity index (CVI) values of each item. Each item with validity index $>0.78$ was included in the final instrument.

\section{Data analysis and processing}

Data was entered by EpiData version 3.1 and analyzed by SPSS version 20. Bivariable and multivariable logistic regressions were used to identify the significance, strength, and direction of the association at 95\% confidence interval. An adjusted odds ratio were used to identify the independent predictors of attitude. All factors with a $P$ value of $<0.2$ in the bivariable analysis were entered in the multivariable model to identify the independent predictors of attitude towards clinical practice. $P$ value of $<0.05$ was used to decide the significance of association at $95 \%$ confidence interval.

\section{Ethical consideration}

Ethical approval and letter of permission were obtained from the College of Health Science, AAU. The letter of permission was submitted to the Nursing and Midwifery Departments, College of Medicine and Health Sciences, UoG to get permission. Following the permission, participants were briefed about the study purpose and the procedure of the data collection process. The privacy of the study participants' and confidentiality of information was maintained.

\section{Result}

Socio-demographic characteristics of study participants

A total of 345 students from the two Departments were participated in the study. Five questionnaire were excluded from the analysis due to gross incompleteness of responses, giving a response rate of $98.6 \%$. Nearly three forth of the study participants were found in age group of 20-24 years (Table 1).

\section{Factors affecting students' attitude towards clinical practice}

Table 2 below revealed the multivariable analysis of factors affecting the attitude of students towards clinical practice among students in UoG. The odds of having favorable attitude were found to be 2 times higher among students who prepared well for clinical practice $[\mathrm{AOR}=2.07,95 \%$, CI $(1.25,3.44)]$ compared with counterparts.

\section{Discussion}

The prevalence of favorable attitude towards clinical practice was $42.9 \%$ in this study which indicates more 
Table 1 Socio-demographic characteristics of Nursing and Midwifery students at UoG, Northwest Ethiopia, 2018

\begin{tabular}{|c|c|c|}
\hline Characteristics & Frequency & Percent (\%) \\
\hline \multicolumn{3}{|l|}{$\operatorname{Sex}(N=340)$} \\
\hline Male & 170 & 50.0 \\
\hline Female & 170 & 50.0 \\
\hline \multicolumn{3}{|c|}{ Age in years $(N=340)$} \\
\hline $15-19$ & 73 & 21.5 \\
\hline $20-24$ & 246 & 72.3 \\
\hline $25-29$ & 19 & 5.6 \\
\hline$\geq 30$ & 2 & 0.6 \\
\hline \multicolumn{3}{|c|}{ Assigned in clinical practice in your stay $(N=340)$} \\
\hline One & 81 & 23.8 \\
\hline Two & 93 & 27.4 \\
\hline Three & 63 & 18.5 \\
\hline Four and above & 103 & 30.3 \\
\hline \multicolumn{3}{|c|}{ Year of study $(\mathrm{N}=340)$} \\
\hline 2nd year & 125 & 36.8 \\
\hline 3rd year & 125 & 36.8 \\
\hline 4th year & 90 & 26.4 \\
\hline \multicolumn{3}{|c|}{ Field of study $(N=340)$} \\
\hline Nursing & 155 & 45.6 \\
\hline Midwifery & 185 & 54.4 \\
\hline \multicolumn{3}{|c|}{ Do you use substance? $(\mathrm{N}=340)$} \\
\hline Yes & 20 & 5.9 \\
\hline No & 320 & 94.1 \\
\hline \multicolumn{3}{|c|}{ Type of substance $(\mathrm{N}=20)$} \\
\hline Chat & 6 & 1.8 \\
\hline Alcohol & 12 & 3.5 \\
\hline Cigarette & 2 & 0.6 \\
\hline \multicolumn{3}{|c|}{ Frequency/week $\mathrm{N}=20$} \\
\hline Daily & 2 & 1.8 \\
\hline 2-4 day/week & 11 & 3.5 \\
\hline Once a week & 7 & 0.6 \\
\hline
\end{tabular}

than half, $(57.1 \%)$ of the study participants had an unfavorable attitude. Unfavorable attitude can lead to poor intent to attend theory and practical sessions $[6$, 17]. Consistent with a previous study [1], seniority was found to be associated with having a favorable attitude towards clinical practice in our study, $55(37.7 \%)$ and 50 (34.2\%) among 4th and 2nd-year students, respectively. Similar with previous studies [18-20], the majority of students (97.9\%) agreed that clinical practice is the major area of Nursing and Midwifery profession in this study. The multivariable analysis revealed that the odds of having a favorable attitude towards clinical practice were found to be 2 times higher among students who prepared well compared with counterparts $[\mathrm{AOR}=2.07,95 \%$, CI $(1.247,3.439)]$. Appropriate preparation before clinical attachment increases students' desire to learn in a clinical setting. The finding is consistent with a study done in Norway [21].

With regards to interaction with staffs, the odds of having a positive attitude towards clinical practice were found to be 2 times higher among students who had good communication with clinical staffs $[A O R=1.89,95 \%, C I$ $(1.05,3.41)]$ compared counterparts. The finding of our study is consistent with previous studies conducted in Jamaica [22], Spain [2], and Iran [3]. This might be due to the fact that clinical staffs are the key stakeholders to shape students with necessary skills, creating conducive clinical-environment, and socializing students with their profession [23]. Similarly, students who practiced in a well-equipped hospital were more likely to have a favorable attitude towards clinical practice compared with counterparts $[\mathrm{AOR}=1.76,95 \%, \mathrm{CI}(1.01,3.06)]$. This might be due to the fact that students could have a better picture of the clinical setup which derives the learning objectives. The finding is supported by the studies done in Australia [8], and Afghanistan [15].

The multivariable analysis indicated that the odds of having favorable attitude were found to be 1.7 times higher among students who were frequently accompanied by clinical-mentors compared with counterparts $[\mathrm{AOR}=1.69,95 \%, \mathrm{CI}(1.018,2.805)]$. This might be due to the fact that clinical mentor can smoothen the relationship between clinical staff and students by bridging gaps. The finding is consistent with the studies done in Norway [21], Iran [24], and Rwanda [23].

\section{Conclusion}

Students who had good communications with clinical staffs, prepared well for clinical practice, practiced in well-equipped hospital, and accompanied frequently by clinical-supervisors in a clinical setting had a favorable attitude towards clinical practice. 
Table 2 Multivariate logistic regression analysis of predictors of attitude towards clinical practice, in UoG, 2018

\begin{tabular}{|c|c|c|c|c|}
\hline \multirow[t]{2}{*}{ Variable } & \multicolumn{2}{|c|}{ Attitude to clinical practice } & \multirow[t]{2}{*}{ COR $(95 \% \mathrm{Cl})$} & \multirow[t]{2}{*}{ AOR $(95 \% \mathrm{Cl})$} \\
\hline & Favorable & Unfavorable & & \\
\hline \multicolumn{5}{|c|}{ Time of assigned in clinical practice } \\
\hline One & 29 (19.9\%) & $52(26.8 \%)$ & 1 & 1 \\
\hline Two & $35(24 \%)$ & $58(29.9 \%)$ & $1.08(0.58,2.01)$ & $1.91(0.84,4.33)$ \\
\hline Three & $28(19.1 \%)$ & $35(18.0 \%)$ & $1.43(0.73,2.81)$ & $2.93(0.91,9.48)$ \\
\hline Four and above & $54(37 \%)$ & $49(25.3 \%)$ & $1.98(1.09,3.59)^{*}$ & $2.08(0.54,7.98)$ \\
\hline \multicolumn{5}{|l|}{ Year of study } \\
\hline 2nd & $50(34.2 \%)$ & $75(38.7 \%)$ & 1 & 1 \\
\hline $3 r d$ & $41(28.1 \%)$ & $84(43.3 \%)$ & $0.73(0.44,1.23)$ & $0.45(0.18,1.12)$ \\
\hline 4 th & $55(37.7 \%)$ & $35(18.0 \%)$ & $2.36(1.35,4.11)^{*}$ & $1.21(0.33,4.45)$ \\
\hline \multicolumn{5}{|c|}{ Prepared for clinical practice } \\
\hline Yes & $69(47.3 \%)$ & $68(35.1 \%)$ & $1.66(1.07,2.58)^{*}$ & $2.07(1.25,3.44)^{* *}$ \\
\hline No & $77(52.7 \%)$ & $126(64.9 \%)$ & 1 & 1 \\
\hline \multicolumn{5}{|c|}{ Communicate well with staff } \\
\hline Yes & $119(81.5 \%)$ & $139(71.6 \%)$ & $1.74(1.04,2.94)^{*}$ & $1.89(1.05,3.41)^{* *}$ \\
\hline No & $27(18.5 \%)$ & 55 (28.4\%) & 1 & 1 \\
\hline \multicolumn{5}{|c|}{ Ready to interact with staffs } \\
\hline Yes & $132(90.4 \%)$ & $151(77.8 \%)$ & $2.69(1.41,5.13)^{*}$ & $2.02(0.97,4.21)$ \\
\hline No & $14(9.6 \%)$ & $43(22.2)$ & 1 & 1 \\
\hline \multicolumn{5}{|c|}{ Staff show respect to students } \\
\hline Yes & $103(70.5 \%)$ & $118(60.8 \%)$ & $1.54(0.98,2.44)$ & $0.82(0.47,1.45)$ \\
\hline No & $43(29.5 \%)$ & $76(39.2 \%)$ & 1 & 1 \\
\hline \multicolumn{5}{|l|}{ Favorable hospital } \\
\hline Yes & $100(68.5 \%)$ & $96(49.5 \%)$ & $2.22(1.42,3.48)^{*}$ & $1.76(1.01,3.06)^{* *}$ \\
\hline No & $46(31.5 \%)$ & $98(50.5 \%)$ & 1 & 1 \\
\hline \multicolumn{5}{|c|}{ Sufficient material in clinical area } \\
\hline Yes & $93(63.7 \%)$ & $95(49.0 \%)$ & $1.83(1.18,2.84)^{*}$ & $1.17(0.69,1.99)$ \\
\hline No & $53(36.3 \%)$ & $99(51.0 \%)$ & 1 & 1 \\
\hline \multicolumn{5}{|c|}{ Attended by supervisor frequently } \\
\hline Yes & $82(56.2 \%)$ & $76(39.2 \%)$ & $1.99(1.29,3.08)^{*}$ & $1.69(1.02,2.81)^{* *}$ \\
\hline No & $64(43.8 \%)$ & $118(60.8 \%)$ & 1 & 1 \\
\hline \multicolumn{5}{|c|}{ The instructor facilitates staff relationship } \\
\hline Yes & $125(85.6 \%)$ & $134(69.1 \%)$ & $2.67(1.53,4.64)^{*}$ & $1.63(0.85,3.11)$ \\
\hline No & $21(14.4 \%)$ & $60(30.9 \%)$ & 1 & 1 \\
\hline \multicolumn{5}{|c|}{ The instructor provides me constructive feedback } \\
\hline Yes & $101(69.2 \%)$ & $110(56.7 \%)$ & $1.71(1.09,2.69)^{*}$ & $1.25(0.73,2.12)$ \\
\hline No & $45(30.8 \%)$ & $84(43.3 \%)$ & 1 & 1 \\
\hline \multicolumn{5}{|c|}{ My pleasure is to meet patient needs } \\
\hline Yes & $142(97.3 \%)$ & $193(99.5 \%)$ & $0.18(0.02,1.66)$ & $0.22(0.02,2.64)$ \\
\hline No & $4(2.7 \%)$ & $1(0.5 \%)$ & 1 & 1 \\
\hline \multicolumn{5}{|c|}{ Maintain patient dignity } \\
\hline Yes & $129(88.4 \%)$ & $183(94.3 \%)$ & $0.46(0.21,1.01)$ & $0.51(0.21,1.28)$ \\
\hline No & $17(11.6 \%)$ & $11(5.7 \%)$ & 1 & 1 \\
\hline
\end{tabular}

NB: * Significate in the binary analysis; ${ }^{* *}$ Significant in the multivariable analysis

$\mathrm{Cl}$ confidence interval, COR crude odds ratio, AOR adjusted odds ratio 
Department of Nursing and Midwifery

\section{(584)}

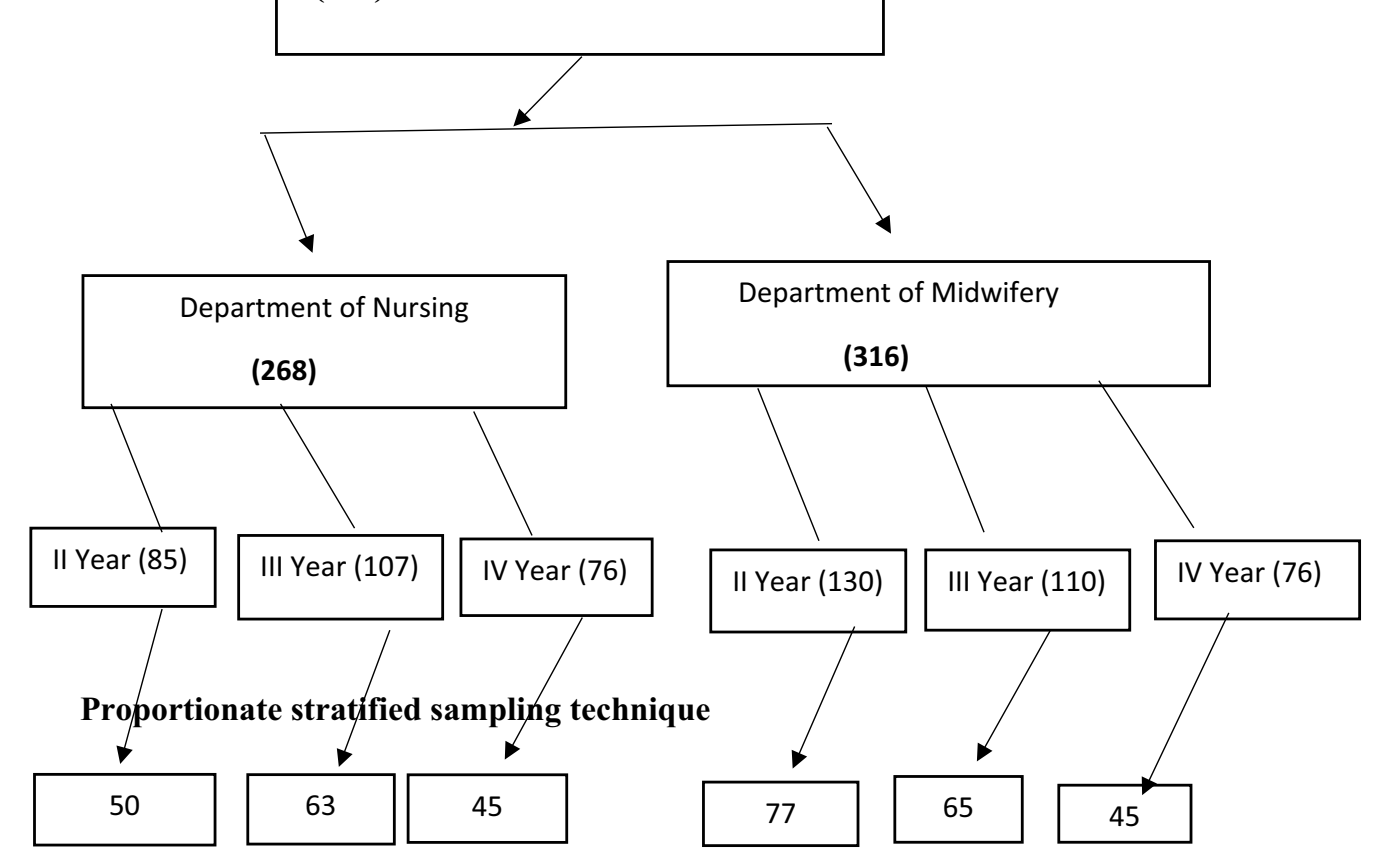

Finally simple random sampling technique until fluffing the total sample by using batch registration as frame

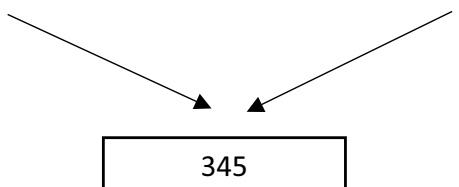

Fig. 1 Sampling procedure for selection of the study participants

\section{Limitation}

The study design is cross-sectional which might be difficult to make cause and effect relationship. Using only a quantitative method might not explicate the real attitude of students related to clinical practice. We have tried to collect data based on the immediate clinical experience of students' which can be taken as a strength.

\section{Abbreviations}

AAU: Addis Ababa University; Cl: confidence interval; UoG: University of Gondar.

\section{Authors' contributions}

YA, WS, WD, and MM have contributed to the design, data collection, thesis write-up, manuscript development, and edition. All authors read and approved the final manuscript.
Author details

${ }^{1}$ Department of Midwifery, Debre Tabor Health Science College, Debre Tabor, Ethiopia. ${ }^{2}$ Department of Nursing and Midwifery, College of Health Sciences, Addis Ababa University, Addis Ababa, Ethiopia. ${ }^{3}$ Department of Midwifery, College of Health Sciences, Debre Tabor University, Debre Tabor, Ethiopia.

\section{Acknowledgements}

The authors are delighted to acknowledge the College of Health Sciences of AAU for securing the ethical review process and for covering the data collection fee. Moreover, the authors would like to express appreciation to study participants.

\section{Competing interests}

The authors declare they have no competing interests.

\section{Availability of data and materials}

The datasets used during the current study are available from the corresponding author on reasonable request.

Consent for publication Not applicable. 


\section{Ethical approval and consent to participate}

The study was approved by the Research Ethics Committee (REC) of the College of Health Sciences, AAU. A written official letter was submitted to the selected departments. Moreover, the purpose of the study was revealed and written consent was obtained from each study participant prior to the initiation of the data collection process. Autonomy of the study participants and the confidentiality of information were maintained.

\section{Funding}

This study has been funded by the College of Health Science of AAU. The funding body has no role in the design, data collection, analysis, and write-up apart from covering the data collection expense.

\section{Publisher's Note}

Springer Nature remains neutral with regard to jurisdictional claims in published maps and institutional affiliations.

Received: 6 January 2019 Accepted: 26 March 2019

Published online: 03 April 2019

\section{References}

1. Fikre R. Assessment of factors affecting clinical practice competency of undergraduate health science Students in Hawassa University, South. Ethiopia. Ann Clin Lab Res. 2016:4(2):69-77.

2. Lapeña-Moñux YR, Cibanal-Juan L, Orts-Cortés M, Maciá-Soler M, Palacios-Ceña D. Nurses' experiences working with nursing students in a hospital: a phenomenological enquiry. Rev. Latino-Am. Enfermagem. 2016;24:e2788. https://doi.org/10.1590/1518-8345.1242.2788.

3. Jamshidi N, Molazem Z, Sharif F, Torabizadeh C, Najafi Kalyani M. The challenges of nursing students in the clinical learning environment: a qualitative study. Sci World J. 2016;2016:1846178. https://doi. org/10.1155/2016/1846178.

4. Karimi S, Haghani F, Yamani N, Najafi Kalyani M. A qualitative inquiry into nursing students' experience of facilitating reflection in clinical setting. Sci World J. 2017:2017:6293878. https://doi.org/10.1155/2017/6293878.

5. Ha E-H. Attitudes toward clinical practice in undergraduate nursing students: AQ methodology study. Nurse Educ Today. 2015;35(6):733-9.

6. Koushali AN, Hajiamini Z, Ebadi A. Comparison of nursing students' and clinical nurses' attitude toward the nursing profession. Iran J Nurs Midwifery Res. 2012;17(5):375

7. Henderson A, Briggs J, Schoonbeek S, Paterson K. A framework to develop a clinical learning culture in health facilities: ideas from the literature. Int Nurs Rev. 2011;58(2):196-202.
8. Peters K, Mclnnes S, Halcomb E. Nursing students' experiences of clinical placement in community settings: a qualitative study. Collegian. 2015:22(2):175-81.

9. Tagney J, Haines C. Using evidence-based practice to address gaps in nursing knowledge. Br J Nurs. 2009;18(8):484-9.

10. Rikhotso SR, Williams MJ, De Wet G. Student nurses' perceptions of guidance and support in rural hospitals. Curationis. 2014;37(1):1-6.

11. Morrison R. Nursing students'attitudes toward people with mental illness: Do they change after instruction and clinical exposure? 2011.

12. UNFPA. Investing In midwives stories from Ethiopia. Addis Ababa, Ethiopia: Federal ministry of Health and UNFPA; 2014.

13. World Health Organization. Global strategic directions for strengthening nursing and midwifery 2016-2020. Geneva: World Health Organization; 2016.

14. Background history of University of Gondar. 2019. http://www.uog.edu. et/ Accessed Jan 252019.

15. Elçigil A, Sarı HY. Facilitating factors in clinical education in nursing. DEUHYO ED. 2011:4(2):67-71.

16. Awuah-Peasah D, Sarfo LA, Asamoah F. The attitudes of student nurses toward clinical work. Int J Nurs Midwifery. 2013:5(2):22-7.

17. Tayebi Z, Dehghan-Nayeri N, Negarandeh R, Shahbazi S. Motives for entering nursing in Iran: a qualitative study. Iran J Nurs Midwifery Res. 2013;18(1):59

18. Kaur L. Assess the attitude of nursing students towards nursing profession. IJAR. 2016;2(6):738-41.

19. Gebrezgabher ZT, Abera GB. Assessment of Nurses Knowledge and attitude towards nursing profession at public hospitals in Mekelle Town, Tigray, Ethiopia. Glob J Med Res. 2017;17:(1-k).

20. Oyedele EA, Emmanuel A, Gaji LD, Goshit JD, Louis OI. Perception of Undergraduate nursing students about nursing profession: a study of University of Jos. Nigeria. Int J Nurs Health Sci. 2015;2(5):60-3.

21. Dale B, Leland A, Dale JG. What factors facilitate good learning experiences in clinical studies in nursing: Bachelor students' perceptions. ISRN Nurs. 2013;2013:628679. https://doi.org/10.1155/2013/628679.

22. Lawal J, Weaver S, Bryan V , Lindo JL. Factors that influence the clinical learning experience of nursing students at a Caribbean school of nursing. J Nurs Educ Pract. 2015;6(4):32.

23. Rajeswaran L. Clinical experiences of nursing students at a selected institute of Health Sciences in Botswana. Health Sci J. 2016;2016:1846178. https://doi.org/10.1155/2016/1846178.

24. Sharif F, Masoumi S. A qualitative study of nursing student experiences of clinical practice. BMC Nurs. 2005:4(1):471-476.
Ready to submit your research? Choose BMC and benefit from:

- fast, convenient online submission

- thorough peer review by experienced researchers in your field

- rapid publication on acceptance

- support for research data, including large and complex data types

- gold Open Access which fosters wider collaboration and increased citations

- maximum visibility for your research: over $100 \mathrm{M}$ website views per year

At $\mathrm{BMC}$, research is always in progress.

Learn more biomedcentral.com/submissions 